"A simple analysis of the effect of the child support grant on school enrolment in South Africa"

AUTHORS Mduduzi Biyase

ARTICLE INFO

Mduduzi Biyase (2016). A simple analysis of the effect of the child support grant on school enrolment in South Africa. Public and Municipal Finance, 5(1), 14-17. doi:10.21511/pmf.05(1).2016.02

DOI http://dx.doi.org/10.21511/pmf.05(1).2016.02

RELEASED ON Tuesday, 19 July 2016

JOURNAL "Public and Municipal Finance"

FOUNDER

LLC "Consulting Publishing Company "Business Perspectives"

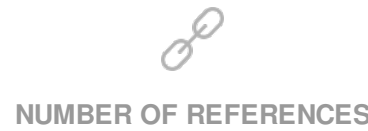

0

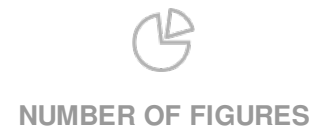

0

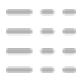

NUMBER OF TABLES

0

C The author(s) 2021. This publication is an open access article. 
Mduduzi Biyase (South Africa)

\title{
A simple analysis of the effect of the child support grant on school enrolment in South Africa
}

\begin{abstract}
This paper studies the impact of the child support grant on school enrolment in South Africa. It is based on the National Income Dynamics Study (NIDS) data set for South Africa for the year 2008. Using the probit model, the author find some encouraging evidence to suggest that indeed the child support grant helps in the way of improving school enrolment in South Africa. More specifically, the author found that the child support grant increases school enrolment by about 10 percentage points.
\end{abstract}

Keywords: National Income Dynamics Study, child support grant, school enrolment, probit. JEL Classification: I38, I21, O15.

\section{Introduction}

Although the transition to democracy raised hopes for many South African people and created conducive conditions for economic growth, South Africassstill faces many development challenges (Nattrass, 2013). A recent report entitled "Hidden hunger in South Africa" concluded that "... despite some progress since the birth of democracy in the country in 1994, one of four people currently suffers from hunger on a regular basis, and more than half of the population live in such precarious circumstances that they are at risk of going hungry" (Oxfam, 2012). The incidence of hunger is not the only problem faced by South Africa - it runs parallel sides with what is commonly known as South Africa's 'triple challenge' of poverty, inequality and unemployment. For example, research shows that unemployment is very high by international standards, with approximately $25 \%$ of the economically active population being jobless. It also shows that South Africa remains one of the most unequal societies in the world, with a Gini coefficient ranging from about 0.66 to 0.69 . These challenges are likely to have a knock on effect on other socioeconomic indicators, such as school enrolment or school attendance. If children grow up in poverty, there are disturbing long-run implications for them and their society. Such children are much more likely to be inadequately educated, to become parents before being ready for the responsibilities. It is against this background of poverty incidence with its long-range severe individual and social implications that the child support grant was introduced in South Africa as a poverty alleviation strategy targeted at children.

This article will attempt to critically review the existing evidence on the impact of cash transfers in general, as reflected in welfare indicators and will pay particular attention to the effect of child support

(C) Mduduzi Biyase, 2016

Mduduzi Biyase, Economics Department University of Johannesburg, South Africa. grant on welfare indicators in the light of recent South African data.

The rest of the paper is organized as follows: section 1 reviews the literature on the effect of cash transfer on socio-economic indicators. Section 2 describes the data and variables used in the statistical analysis. Section 3 describes the method used. The final section, present the results and provide some concluding remarks, respectively.

\section{Literature review}

Several empirical studies have been provided regarding the relationship between child support grant/conditional cash transfer and several dimensions of socioeconomic well-being such as school enrolment. These studies include the works of Dubois et al. (2011) on Mexico, Kondratjeva (2010) on Mozambique, Williams (2007) on South Africa, de Brauw at al. (2008) on Mexico, Cardoso (2004) on Brazil, Chaudhury et al 2010 on Punjab (Pakistan), Samson et al. (2008) on South Africa, Skoufias and Parker (2001) on Mexico, Muralidharan et al. (2013) on India, Eyal and Woolard (2013) on South Africa, Kaziaga and de Walque (2013) on Burkina Faso, Bundlender and Woolard (2006) on South Africa, Heinrich et al. (2012) on South Africa, Behrman and Parker (2010) on Latin America, Samson et al. (2004) on South Africa, Schady and Arajo (2006) on Ecuador, and Maluccio and Flores (2005) on Nicaragua.

Samson and Heinrich (2009) applied the propensity score matching method to examine the impact of child support grant in South Africa. After adjusting for the differences between the treatment and the control groups, the authors concluded that the impact on the beneficiaries of the child support grant on reducing hunger was 2 to 3 times higher than the unmatched differences of 0.024 . In addition, Samson and Heinrich (2009) noted that the beneficiaries of child support grant had a positive and statistical by significant impact on school enrolment. 
Kondratjeva (2010) used panel data and a difference-in-differences method, regression analysis and propensity score re-weighting method to investigate the impact of unconditional cash transfer on school enrolment in Mozambique. They found evidence to suggest a positive change in school enrolment among school age children.

De Brauwat et al. (2008) used data from the evaluation survey conducted in May and June of 1999 to examine the impact of conditioning transfers on school enrolment in Mexico. Employing the most recent econometric approaches, including nearest neighbor matching and household fixed effects regressions, they find that children whose attendance was monitored had higher enrolment rates compared to children whose attendance could not be monitored, even after control for observable household characteristics.

In their paper, Chaudhury et al. (2008) examined the impact of the female school stipend program on public school enrolments in Punjab, Pakistan. Using data from the provincial school censuses 2003 and 2005 and various econometric methods, including difference-in-differences (DD), triple differencing (DDD) and regression-discontinuity design (RDD), they found a modest, but statistically significant impact of the intervention.

Using data from a large representative household survey and triple differencing approach (using boys and the neighboring state of Jharkhand as comparison groups), Muralidharan et al. (2013) investigated the impact of conditional cash transfer on school enrolment in India. Their results suggest that girls that were exposed to the program experienced a significant increase in enrollment in secondary school by $30 \%$.

Nicaragua Maluccio and Flores (2005) found that the Red de la Proteccion Social induced a 17.7 percentage point increase in school enrolment and school attendance (20 percent) for the targeted group. Moreover, the program also induced an average net increase of 7.3 percentage points for the students in grade 1 to 4 . For Honduras, Glewwe and Olinto (2004) found that the Programa de Asignacion Familiar (PRAF) was responsible for a 1 to 2 percentage point increase in school enrolment, and a 2 to 3 percentage point reduction in school dropout rate. Schady and Araujo (2006), in Ecuador, using a randomized experiment, showed that the CCT had a bigger impact of approximately 10 percentage point increase in school enrolment.

\section{Data and variables used}

This study uses the National Income Dynamics Study (NIDS) collected in South Africa by the Southern African Labor and Development Research
Unit (SALDRU). The NIDS is an ongoing longitudinal panel survey with representative data for the South African population. During the first wave, 7683 households were interviewed, generating a sample of over 28,000 persons. NIDS has been conducted since 2008, and covers many topics such as household's positive or negative shocks (a death in the family or an unemployed relative obtaining a job).

2.1. Variables used. Our dependent variable is school enrolment and was constructed as a $0-1$ binary variable based on the answer to the question asked in the the National Income Dynamics Study data: "Is this child currently enrolled in school?" Those who answered "Yes" were coded as 1 , otherwise, those who answered "No" coded as 0 . The relevant regressors were drawn from the existing empirical literature in this field: child support grant (our variable of interest), mother's education, father's education, household size, categorical variables gender $(1=$ male, $0=$ female $)$. We also included a dummy-coded variable for the Provinces where the children resides (Western Cape as reference category, household in Eastern Cape (1/0) household in Northern Cape (1/0), household in Free State (1/0), household in KwaZulu-Natal (1/0) household in North West (1/0), household in Gauteng (1/0), household in Mpumalanga (1/0), household in Limpopo $(1 / 0))$, etc.

\section{Methodology}

Given the dichotomous nature of the dependent variable in our study, a probit model is used to estimate the effect of child support grant on school enrolment.This model has been frequently used in many studies in this field. One of the reasons for the frequent use of this model is, probably, the ease of usage. The probit model we estimate is of the following form:

$$
E_{i}^{*}=x_{i} \beta+\varepsilon_{i} \varepsilon_{i} \sim N\left(0, \sigma^{2}\right),
$$

where:

$$
\begin{aligned}
& E_{i}=1 \text { if } E_{i}^{*}>0 \\
& E_{i}=0 \text { if } E_{i}^{*} \leq 0,
\end{aligned}
$$

where: $E$ is the current school enrolment status, $x$ is a vector of explanatory variables (e.g., mother's education, father's education, household size, categorical variables, etc.); $\beta$ is coefficient to be estimated and $\varepsilon_{i}$ is a stochastic error term. The coefficients obtained in the probit estimation serve only to provide a sense of the direction of the effects of the covariates on the dependent variable, and cannot be used for magnitude impact analysis. To examine the magnitude of impact, the marginal impact of the explanatory variables on the probability of current school enrolment is provided.

\section{Results}

Table 1 presents the results of the impact of child support grants and school enrolment in South Africa. 
Consistent with previous studies in South Africa (Case, Hosegood and Lund, 2005; and Samson et al., 2004), we find that the child support grant increases the likelihood of school enrolment. In particular, we found that receiving the child support grant leads to 10 percentage point increase in the probability of school enrolment. This finding is to be expected because the child support grant is likely to improve other socioeconomic indicators such as children's health and nutrition, which, in turn, positively contribute to their school readiness (Case, Hosegood and Lund, 2005).

Table 1. Probit estimates of child support grant effects of on enrolment

\begin{tabular}{|l|c|c|}
\hline \multicolumn{1}{|c|}{ Variable } & Coefficient & $\mathrm{t}$-stats \\
\hline CSG & 0.100025 & 2.97 \\
\hline urban & 0.0534464 & 1.63 \\
\hline rural & 0.1606167 & 3.82 \\
\hline coulard & 0.0638491 & 1.19 \\
\hline indians & 0.0617028 & 0.32 \\
\hline whites & -0.0565375 & -0.84 \\
\hline Eastern Cape & -0.0407139 & -0.65 \\
\hline Northern Cape & 0.0692133 & 1.11 \\
\hline Free State & -0.0113936 & -0.17 \\
\hline KwaZulu-Natal & 0.0248991 & 0.45 \\
\hline North West & 0.0419325 & 0.64 \\
\hline Gauteng & 0.0563763 & 1.05 \\
\hline Mpumalanga & -0.0506183 & -0.81 \\
\hline Limpopo & -0.350425 & -5.45 \\
\hline Hhsize & 0.0105498 & 1.25 \\
\hline Hhunepl & 0.0831369 & 2.56 \\
\hline Hhmarried & 0.1328465 & 3.12 \\
\hline Mothers ED & 0.0008021 & 1.24 \\
\hline Fathers ED & 0.0012864 & 2.25 \\
\hline
\end{tabular}

\section{References}

1. Behrman, J. and Parker, S. (2010). The impact of conditional cash transfer on education in conditional cash transfers in Latin America: A magic bullet to reduce poverty? Ed. By M. Adato and J. Hoddinott (Baltimore: Johns Hopkins University Press).

2. Cardoso, E. and Souza, A.P. (2003). The impact of cash transfers on child labour and school attendance in Brazil.

3. Case, A., Hosegood, V. and Lund, F. (2005) The reach and impact of Child support grants: evidence from KwaZulu-Natal, Development Southern Africa, 22 (4), pp. 467-482.

4. Chaudhury, N. and Parajuli, D. (2008) Conditional cash transfers and female schooling: the impact of the female school stipend programme on public school enrolments in Pubjab, Pakistan. Applied Economics.

5. De Brauw, A., Gilligan, D., Hoddinott, J. and Roy, S. (2014). The impact of Bolsa Familia on schooling: girls advantage increases and older children gain. International Food Policy Research Institute. IFPRI Discussion Paper 01319.

6. Dubois, P., de Janvry, A. and Sadoulet, E. (2012). Effects on School Enrollment and Performance of a Conditional Transfers Program in Mexico, Journal of Labor Economics, 30 (3), pp. 555-89.

7. Eyal, K. and Woolard, I. (2013). School enrollment and the child support grant: evidence form South Africa. Cape Town. SALDRU, University of Cape Town. SALDRU Working Paper Number 125/NIDS Discussion Paper 2013/7.

8. Glewwe, P. and Olinto, P. (2004). Evaluating the impact of conditional cash transfers on schooling: An experimental analysis of Honduras. Final Report for USAID. World Bank. Washington.

9. Heinrich, C., Hoddinott, J. and Samson, M. (2012). The impact of South Africa's child support grant on schooling and learning. Pretoria: SASSA.

10. Kondratjeva, O. (2010). Quantitative Impact Assessment of Mozambique's Cash Transfer Pilot Program. Honors Thesis, Williams College.

11. Maluccio, J.A. and Flores, R. (2005). Impact evaluation of a conditional cash transfer program: The Nicaraguan Red de Protección Social. FCND Discussion paper No. 184. Food Consumption and Nutrition Division (FCND). International Food Policy Research Institute (IFPRI). Washington. 
12. Muralidharan, Karthik and Nishith Prakash. (2013). Cycling to School: Increasing Secondary School Enrollment for Girls in India. NBER Working Paper No. 19305.

13. Samson, M., Lee, U., Ndebele, A., MacQuene, K., van Niekerk, I., Ghandhi, V., Harigaya, T. and Abrahams C. (2004). The social and economic impact of South Africa's Social Security System, EPRI Research Paper 37. Cape Town.

14. Skoufias, E. and Parker, S. (2001). Conditional caash transfer and their impact on child work and schooling: evidence from PROGRESA program in Mexico, Economia, 2 (1), pp. 45-96

15. Schady, N. R. and Araujo, M. (2006). Cash transfers, conditions, school enrollment, and child work: Evidence from a randomized experiment in Ecuador (Vol. 3). World Bank Publications.

16. Williams, J. (2007). Social change and community participation: the case of Health Facilities Boards in the Western Cape of South Africa, in: A. Cornwall and V. Coelho (eds) Spaces for Change? The Politics of Participation in New Democratic Arenas (London: Zed Books), pp. 95-113. 